Morrison School of Agribusiness and Resource Management Faculty Working Paper Series

\title{
Sales by Multi-Product Retailers
}

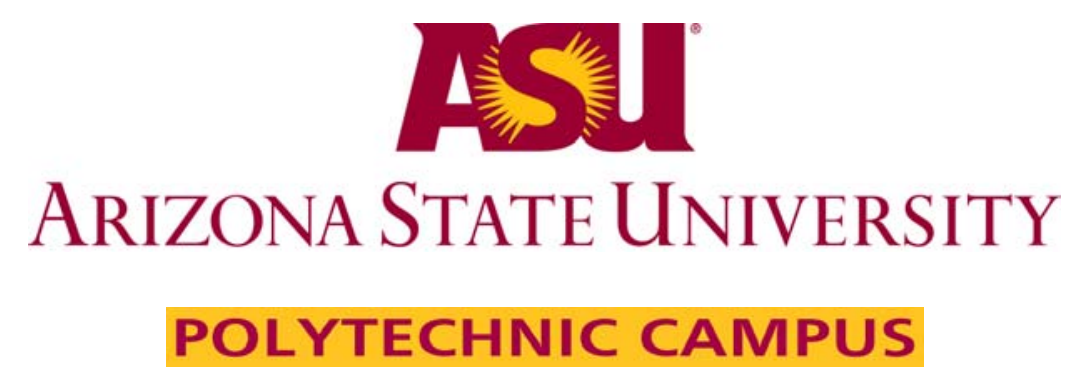




\section{Sales by Multi-Product Retailers}

\section{Introduction}

Supermarkets use periodic price promotions, or "sales" on a regular basis for a variety of products. Although the economic rationale underlying sales for fashion items (Pashigian 1988; Epstein 1998), consumer durables (Varian 1980; Blattberg, Eppen, and Lieberman 1981) and storable food products (Pesendorfer 2002; Hosken and Reiffen 2001) is well established, relatively little is understood about why supermarkets promote perishable items such as fresh fruits and vegetables, dairy products or meat. This relative lack of attention is particularly surprising given the importance fresh produce plays in attracting consumers to an individual store (Produce Marketing Association 2001) and the average profitability of perishable items. While the literature on price dispersion offers many alternative explanations for why sales are used and how they can exist in equilibrium, few theoretical models recognize the dominant feature of food retailing. Namely, supermarkets sell multiple products that meet often complementary needs. Such demand complementary can explain the existence of loss-leaders in a retail environment (Holton 1957; Bliss 1988), but not the precise number of products offered on sale each week, nor the size of the discount. Indeed, there is very little research that addresses the interdependent roles of the depth and breadth of price promotion among multi-product perishable-good retailers.

The primary contribution of this paper lies in demonstrating that sales among perishable food items are mixed-strategy equilibria among multi-product retailers in which managers choose both the size of the promotion and the number of products to promote. A simple theoretical model shows that the number of products offered for sale and the depth of their discount are complementary tools in increasing both share and category volume. Tests of this hypothesis are conducted within a general model of differentiated-products retail equilibrium by estimating both demand and price-setting equations in a framework similar to recent studies by Chintagunta (2002), Nevo (2001), Besanko, Gupta and Jain (2001) and Cotterill, Putsis and Dhar (2000). In this way, we derive a set of empirical rules governing the choice of promotional breadth and depth

as well as an estimate of the impact of price promotion on both product- and category-level demand. Based 
on results obtained by estimating this model using detailed, comprehensive retail scanner data for several important perishable product categories, we find that perishable products are indeed offered as loss-leaders, and not simply loss-makers.

\section{Rationale for Price Promotion}

Theories of why retail firms may find it rational to periodically reduce prices, and then raise them again shortly thereafter, revolve around a few key assumptions regarding either the structure of the market, firm behavior, or consumer behavior. First, violations of the "law of one price" can arise within a competitive equilibrium provided consumers differ in the cost of search (Stigler 1961; Rob 1985), the degree of priceinformation they possess in an ex ante or buy in an ex post sense (Varian 1980; Burdett and Judd 1983; Carlson and McAfee 1983), their cost of inventory holding (Blattberg et al. 1981; Aguirregabiria 1999), their loyalty to a particular store (Villas-Boas 1995; Pesendorfer 2002) or their intensity of demand (Jeuland and Narasimhan 1985; Pesendorfer 2002) or if firms differ in their costs of production (Reinganum 1979).

Second, a price promotion can also be the result of price discrimination by a retailer who allocates goods among high-value and low-value consumers either at one point in time (Salop 1977; Salop and Stiglitz 1977; Narasimhan 1984; Banks and Moorthy 1999), or over time as low-valuation consumers accumulate prior to a sale (Stokey 1979; Conlisk, Gerstner and Sobel 1984; Sobel 1984; Landsberger and Meilijson 1985). Third, promotions may arise if retailers are uncertain regarding the level of demand so must reduce prices in order to attract enough customers to clear their inventory (Rothschild 1974; Lazear 1986; Pashigian 1988). Fourth, retailers may conduct sales for strategic reasons, perhaps as trigger strategies designed to implicitly support a collusive oligopoly (Green and Porter 1984; Lal 1990) or out of a recognition that low prices now will invite relatively benign punishments from rivals (Rotemberg and Saloner 1986). Fifth, managers often regard price promotion as an essential part of introducing a new product (Bass 1980; Spatt 1981). None of these explanations, however, are appropriate in a retail food marketing environment where

products are perishable, retailers sell multiple, possibly complementary, goods and individual stores tend to interact in highly competitive local markets. While much of the theoretical and empirical research relies on intertemporal price discrimination to explain sales of fashion items, durable goods or storable products, 
supermarkets using a HI-LO or promotional pricing strategy typically offer sales on perishable items on a daily basis. Because perishable goods tend to be purchased frequently, at regular intervals and are typically not stored for long, intertemporal price discrimination can be ruled out. Nonetheless, price discrimination that exploits other sources of variation in willingness to pay among consumers is still plausible. In fact, many consumers are loyal to a particular store for reasons of geographic proximity, product assortment, store attributes, or due to the effectiveness of a frequent shopper program. Moreover, with the importance of fresh produce to overall supermarket sales, motivations that exploit the complementarity of produce demand with other items may be particularly important.

Indeed, the dominant rationale given by retail managers for using price promotions is to build store traffic, or use sale products as "loss leaders." ${ }^{1}$ Loss-leaders are products that are offered at a sufficiently deep discount to attract consumers to the store and, while buying the loss-leader, purchase other relatively high margin products at the same time. Hess and Gerstner (1987), Bliss (1988), Epstein (1988), Lal and Matutes (1995), McAfee (1995) and Hosken and Reiffen (2001) explicitly allow for multiple-product interactions typical of food retailing, but do not provide convincing empirical evidence that loss-leaders, or even complementarity, are significant factors driving price promotions among food products. Bliss (1988) explains the existence of loss-leaders by suggesting that retailers price according to Ramsey taxation rules such that losses on one product are made up by profits on others. Lal and Matutes (1994) specify a model in which loss-leader sales increase total firm profit by generating higher store traffic. According to their logic, shopping involves significant economies of scale so, once attracted to a store through loss-leading promotions, consumers minimize per unit search costs by buying other items on the same trip. Hess and Gerstner (1987) develop a similar model in which they show that demand complementarity can cause retailers to offer lossleaders and "rain checks" that allow consumers to receive the same deal in the future if the loss-leader sells out on a particular day. Giulietti and Waterson (1997) offer a multi-product retail pricing model similar to Bliss (1988) which admits the possibility of loss-leaders, but use this model to explain only continuous price variation and not periodic sales. Epstein (1988), on the other hand, develops a multi-product version of van Praag and Bode (1992) in which he maintains the dominant rationale for sales among fashion goods

\footnotetext{
${ }^{1}$ Commonly, a loss leader is a product that is advertised and sold below marginal cost in order to attract buyers to purchase other, related items in a multi-product retail environment.
} 
is the ability of sales among some goods to increase demand for others. Without relying as explicitly on potential complementarity, McAfee (1985) presents a multi-product version of Burdett and Judd's (1983) price dispersion model. In this model, cross-sectional price variation is driven by a lack of ex post price information on the part of some consumers for commodities within a particular group, some of which may, in fact, be loss-leaders. In the closest theoretical model to this research, Hosken and Reiffen (2001) develop a model of perishable and non-perishable product sales in which increased revenue from non-discounted perishables supports deep price discounts among non-perishable products. Their model assumes, however, that retail managers price all products with cross-category considerations firmly in mind. This is not the case in reality. Moreover, their empirical analysis provides only weak support for the hypotheses of their model. Indeed, despite the theoretical importance of complementarity, empirical support for the effectiveness of loss-leaders remains elusive.

Pesendorfer (2002) tests the impact of promotional pricing for ketchup on the demand for detergent, soup and yogurt sales in the same store and finds little empirical support for the sales externalities that would be expected of a loss-leader. These other products, however, are sufficiently unrelated to ketchup that we would expect the loss-leader impact to be of second-order magnitude if present at all. Rather, any loss-leader evidence is more likely to be contained to the same general product category within the store among goods that are complementary and not independent in demand. Nonetheless, Walters and McKenzie (1988) find results similar to Pesendorfer in a sample of weekly supermarket sales and profit performance for two stores over a 131 week period. On a weekly basis, only one of eight loss-leaders caused store traffic to increase and none were profitable, while double couponing was more profitable, but not due to a traffic effect. These results are also supported by findings by Arnold, Oum and Tigert (1983) in a broader study of the determinants of supermarket choice, who find that store location, overall low prices, and cleanliness are more important drivers of store traffic than weekly specials. Other studies in the marketing literature, however, find that price promotions, if not loss-leaders, are effective in increasing product and category sales.

Empirical work in this area finds that sales can impact demand in several ways. First, Blattberg, Eppen, and Lieberman (1981), Neslin, Henderson and Quelch (1985), and Bucklin and Gupta (1992) each estimate the effect of promotion on some type of contemporaneous consumer choice - what brand to choose, how 
much to buy, or when to buy it, while Gupta (1988) estimates all three. Gupta (1988) is notable in that he finds most of the sales increment due to price promotion for ground coffee comes from brand switching (84\%), while only $14 \%$ is due to purchase acceleration and $2 \%$ due to stockpiling (a 14/84/2 rule). Pauwels, Hanssens, and Siddarth (2002), on the other hand, suggest that price promotions are likely to have significant dynamic components arising from both adjustment effects or permanent impacts and find that a $39 / 58 / 3$ breakdown is a better description of long-run consumer response to a price promotion. Clearly, much more of the sales impact comes from an increase in purchase incidence relative to brand switching while very little is due to increased purchase volumes. Similar acceleration effects in highly perishable items, however, may lead to greater overall consumption because inventories cannot be held for long. Nijs et al. (2001) report evidence of superior promotion effectiveness for perishable products in a two-stage econometric model in which they first estimate response parameters among a large number of product categories using a VARX model and then explain differences in response in a second-stage generalized least squares approach. Other recent studies of the impact of promotion on purchase behavior go beyond estimation of the "primitive" elasticities of incidence, choice and quantity to conduct meta-analyses of the response parameters themselves. Bell, Chiang and Padmanabhan (1999) use this approach to find that storability has a positive effect on primary demand response to promotions (quantity, but not incidence) as well as a positive effect on secondary demand, or brand choice.

A second group of studies investigates not only whether price promotions impact demand, but consumer behavior more generally in terms of their brand loyalty or price sensitivity (Lattin and Bucklin 1989; Guadagni and Little 1983). These studies find that frequent promotions tend to reduce consumers' sensitivity to price changes as they come to expect and anticipate periodic price reductions. While loyalty is clearly relevant to retailer profitability, few empirical analyses study the direct impact of price promotions on store traffic. Whereas Walters and MacKenzie (1988) find little empirical rationale for using loss-leaders, more recent research by Dreze (1995) and Chintagunta (2002) finds that retailers do indeed tend to use promotions on national brands to attract more customers. In doing so, Chintagunta (2002) applies a random coefficient logit model of consumer demand and optimal pricing developed by Berry (1994) and Berry, Levinsohn and Pakes (1995) to a detailed chain-level data set of retail pain-killer sales. While this approach 
offers advantages of flexibility, parsimony and robustness, it is unable to estimate the impact of promotions on market-size, as opposed to market-share. Consequently, in order to test the effect of promoting perishable goods on store volume, this study develops a two-level model of category volume and product share similar to Hausman (1997) while accounting for the endogeneity of discount prices and the number of products offered each week. In this way, the model is not only able to test whether price promotions are able to generate incremental store traffic, but also whether they are consistent with a theoretical explanation for retail sales.

\section{Theoretical Model of Price Promotions for Perishable Products}

In this model, promotions are offered on perishable products in a competitive, multi-product, retail environment where storage and, hence, intertemporal price discrimination, is not possible. Assuming market size and number of products that form a typical "shopping basket" are fixed, the total demand facing an individual store is equal to its share of consumers multiplied by the number of products. Retailers use price promotions to increase market share, or store traffic. Each consumer, therefore, is assumed to purchase only one unit of each good. There are two types of consumers. Loyal consumers purchase from a particular store either because of geographic proximity (transportation costs), store-preference or a lack of information as to lower cost alternatives. Non-loyal consumers, on the other hand, shop among stores for the lowest price for their entire "basket" of goods. Retailers compete for non-loyal consumers, or "shoppers," using both discount depth and the number of sale products offered, or breadth of the sale. In other words, non-loyals shop while retailers offer a greater number of goods on sale. Demand accumulates across stores until a retailer has sufficient incentive to offer enough sale goods to attract the non-loyals. Once non-loyals find this store, they buy immediately. This process is similar to the dynamic models of Sobel (1984) or Pesendorfer (2002), but latent demand builds over stores rather than time and consumers do not differ in their maximum willingness to pay. Consumers buy from only one store because it is assumed that shopping entails sufficient economies of scale so that further shopping is never optimal (Warner and Barsky 1995).

Formally, the model is a static, multi-product generalization of Pesendorfer (2002). It differs, however, primarily in that perishability rules out intertemporal demand accumulation among shoppers. Rather, a multi-product retail assortment ensures that demand builds horizontally, or among consumers who vary in 
their willingness to shop. Specifically, assume each of $j=1,2,3, \ldots, m$ retailers sells $i=1,2,3, \ldots, n$ products, where products are either offered for sale $\left(n_{1}\right)$, or not $\left(n_{2}\right)$ so that $n=n_{1}+n_{2}$. Loyal consumers constitute a proportion $\alpha_{i} / m\left(0<\alpha_{i}<1\right)$ of all consumers, while there are $\left(1-\alpha_{i}\right)$ non-loyals. Loyals do not shop for the lowest-price product, so purchase from store $j$ so long as the price is below their reservation price for that product, $v_{h i}$. All consumers buy an entire basket of $n$ goods each period, so loyals purchase $n_{1}+n_{2}$ from store $j$ whether there is a sale or not. If there is no sale, they buy all $n$ products at the non-sale price. On the other hand, non-loyals seek the lowest cost basket of $n$ goods by shopping among all $m$ retailers. Therefore, they search fo the store that offers the most products on promotion, and buy all products offered for sale at the discount price $\left(p_{i}\right)$ if this price lies below the reservation price, $v_{h i}\left(v_{h i}>p_{i}\right)$. Retailers pay a random wholesale price $c_{i}$, however, it is not necessary for $c_{i}$ to lie below the sale price for each product provided that total store profit is greater than zero, thus admitting the possibility of a true loss leader. By shopping among stores, shoppers reduce the average price they pay for their entire basket by not buying until they find a set of prices they are willing to pay. Retailers compete for shoppers by varying the number of sale products offered. As potential demand accumulates within the category, competing retailers will offer more and more goods on sale until shoppers are induced to buy. The "winning" retailer receives all of the non-loyal business, selling all $n_{1 j}$ goods to non-loyals and $n_{2 j}$ to loyals at the sale price where $n_{1 j}=\max \left[n_{11}, n_{12}, n_{13}, \ldots n_{1 m}\right]$. In this way, selling non-sale products to shoppers compensates retailers for the lower margins received during a sale period. Implicitly, therefore, this mechanism describes the complementarity between leaders and other goods that is key to multi-product retail pricing as described by Holton (1957), Bliss (1988), or Giulietti and Waterson (1997).

To further simplify the solution, assume also that the proportion of each consumer-type, the total number of consumers and all prices are symmetric among the goods. Given both the share and category effects of a sale, total store profit during a promotion is:

$$
\pi_{j}=\sum_{i \in n_{2 j}}\left(\alpha_{j} / m+(1-\alpha)\right)\left(v_{h, i j}-c_{i j}\right)+\sum_{i \in n_{1 j}}\left(\alpha_{j} / m+\left(1-\alpha_{j}\right)\right)\left(p_{i j}-c_{i j}\right)
$$

where $n_{1 j}$ is the number of sale-priced goods offered by retailer $j$. The intuition underlying this specification 
of the demand function is straightforward. Retailers would like to charge the highest possible price for all products, but recognize that the latent demand from non-loyal consumers builds as they search over stores that do not offer a sufficient number of sale products to attract them. Once a certain critical mass of shoppers is reached, it pays a retailer to cut his price on more products, thereby attracting this entire group of shoppers. Clearly, the value of $n_{1 j}$ must be such that each retailer has an incentive to avoid offering all $n_{j}$ products on sale, thus immediately earning the entire market. In the absence of a sale, however, retailers sell all $n_{j}$ goods to only their loyal customers at their reservation, or list price. If this is the case, Sobel (1984) shows that the retailer effectively has a monopoly over its loyal customers, so derives a total profit of:

$$
\pi_{j}=\sum_{i \in n_{j}}\left(\alpha_{j} / m\right)\left(v_{h, i j}-c_{i j}\right)
$$

by selling all $n_{j}$ products to loyal customers at their reservation price.

Varian (1980) shows that there is no pure-strategy equilibrium to such a pricing game. Rather, he uses the logic developed by Butters (1977) in arguing that price dispersion among stores can be supported as a mixed strategy equilibrium. In order for a mixed strategy equilibrium (MSE) to exist, the amount of expected profit earned by using a price promotion strategy must be the same as that expected to be earned from focusing entirely on high valuation consumers. To solve for the price distribution underlying the MSE, however, it is first necessary to describe the way in which retailers set prices.

Each retailer sets its price and promotion strategies for all products simultaneously. Supermarkets are assumed to be monopolistically competitive as stores are differentiated by location and other factors, but make zero economic profits after competing in prices. Therefore, each retailer decides whether to price at consumers' reservation price, or to set a promotional price below this level and, if he decides to offer a sale, how many products to discount. In setting these prices, a retailer observes the state of demand as summarized by his share of the market $\left(\alpha_{j} / m\right)$ and uncertain wholesale prices, $c_{i j}$. Retailers will only supply a set of products $n_{j}$ if the total profit attainable is non-negative. Therefore, conditional on the state of demand, assume the price of each product $i$ offered by firm $j$ is drawn from a marginal probability density function $f_{i j}\left(p_{i j}\right)$ with corresponding distribution function $F_{i j}\left(p_{i j}\right)$. This density function defines the randomization strategy retailers use to compete for non-loyal consumers. In doing so, however, firm $j$ will offer the lowest 
price on product $i$ only if all other $-j=1,2, \ldots, m-1$ firms offer a higher price. Assuming symmetric price distributions, firm $j$ will have the lowest price with probability $\left(1-F_{i j}\left(p_{i j}\right)\right)^{m-1}$. Therefore, at least one of the other $m-1$ firms will offer a lower price on product $i$ with probability $\left(1-\left(1-F_{i j}\left(p_{i j}\right)\right)^{m-1}\right)$, and thereby count one product toward its total offering of the largest number of promotional products for that week. Assuming the marginal price distributions are symmetric over both products and firms, the joint distribution over all $n_{1 j}$ products offered on sale by each firm is:

$$
F_{-j}(\mathbf{p})=\left(1-\left(1-F_{i j}\left(p_{i j}\right)\right)^{m_{j}-1}\right)^{n_{1 j}}
$$

which is the distribution of the lowest price offered by firms other than firm $j$ defined now, of course, over a vector of prices. To solve for the specific form of the price distribution of firm $j$, it is necessary to first solve for the profit of firm $j$ in terms of $F_{-j}(\mathbf{p})$ and then solve for $F_{j}(\mathbf{p})$ in terms of the parameters of the profit function. In this way, both the form and existence of a mixed strategy equilibrium in loss-leaders is derived.

Taking the price distribution as given, the expected profit for firm $j$ during a sale period is the sum of profit from loyal and non-loyal consumers buying each product multiplied by the probability of winning the non-loyal market:

$$
E\left[\pi_{j}\right]=\left(\sum_{i \in n_{2 j}}\left(\alpha_{j} / m+\left(1-\alpha_{j}\right)\right)\left(v_{h, i j}-c_{i j}\right)+\sum_{i \in n_{1 j}}\left(\alpha_{j} / m+\left(1-\alpha_{j}\right)\right)\left(p_{i j}-c_{i j}\right)\right)\left(1-F_{-j}(\mathbf{p})\right)
$$

But, the mixed strategy equilibrium requires this level of profit to equal the profit during non-sale periods in which the firm sells only to loyal consumers, or:

$$
\begin{aligned}
& \sum_{i \in n}\left(\alpha_{j} / m\right)\left(v_{h, i j}-c_{i j}\right) \\
& =\left(\sum_{i \in n_{2 j}}\left(\alpha_{j} / m+\left(1-\alpha_{j}\right)\right)\left(v_{h, i j}-c_{i j}\right)+\sum_{i \in n_{1 j}}\left(\alpha_{j} / m+1-\alpha_{j}\right)\left(p_{i j}-c_{i j}\right)\right)\left(1-F_{-j}(\mathbf{p})\right),
\end{aligned}
$$


Solving for the distribution of the minimum prices charged by all other $m-1$ gives:

$$
F_{-j}(\mathbf{p})=\left(1-\frac{\sum_{i \in n}\left(\alpha_{j} / m\right)\left(v_{h, i j}-c_{i j}\right)}{\sum_{i \in n_{2 j}}\left(\alpha_{j} / m+\left(1-\alpha_{j}\right)\right)\left(v_{h, i j}-c_{i j}\right)+\sum_{i \in n_{1 j}}\left(\alpha_{j} / m+\left(1-\alpha_{j}\right)\right)\left(p_{i j}-c_{i j}\right)}\right) .
$$

Assuming symmetry among products, firm $j$ draws its sale prices from a joint distribution over $n_{1 j}$ products on the support $\left[v_{h j}, c_{j}\right]$, which, given (3) above, is defined as:

$$
\begin{aligned}
F_{j}(\mathbf{p}) & = \\
& =\mathbf{1}-\left(1-\left(1-\frac{n_{j}\left(\alpha_{j} / m\right)\left(v_{h, j}-c_{j}\right)}{n_{2 j}\left(\alpha_{j} / m+\left(1-\alpha_{j}\right)\right)\left(v_{h, j}-c_{j}\right)+n_{1 j}\left(\alpha_{j} / m+\left(1-\alpha_{j}\right)\right)\left(p_{j}-c_{j}\right)}\right)^{1 / n_{1 j}}\right)^{1 /\left(m_{j}-1\right)} .
\end{aligned}
$$

for each store $j$. Because this distribution represents an equilibrium pricing strategy, retailers always offer some products priced at the promotional level in order to attract otherwise non-loyal customers, or traffic. In practice, this equilibrium provides a snapshot of one point in a process by which a retailer offers an increasing number of products for sale, selling only to his loyal customers, until eventually offering the most discounted products in the market. At this point, he captures all of the non-loyal shoppers in the market and sells this group both the discounted and non-discounted products. If this distribution does indeed describe but one point in an ongoing pricing competition between retailers, then a winning retailer maintains $n_{1 j}$ goods on promotion until another retailer offers more. Although this may appear to lead to a convergent process whereby retailers offer more and more products on sale until every store follows an everyday-low-price (EDLP) strategy, it may instead explain the movement of grocery retailers toward supercenter and club-store formats, where one benefit is the ability to offer a wider assortment of products on sale each week. In order to test whether (7) represents a realistic description of pricing practice, we use the limits of support for $F_{j}(\mathbf{p})$ to solve for two structural equations - for the number of sale products and magnitude of the discount - that are amenable to econometric estimation as part of the broader impact-testing process. Moreover, specifying a more general econometric model of total store sales provides estimates of each strategy's effect on total store sales.

While equation (7) shows how price dispersion in a multi-product environment can be an equilibrium 
outcome, the model developed here is as much one of promotional breadth as it is a rationalization for price dispersion. The breadth of a promotion, defined as the number of products on sale in equilibrium, is found by solving for $n_{1 j}$ at the lower support of (7), or where the probability of store $j$ offering the lowest price is zero, or $F_{j}(\mathbf{p})=\mathbf{0}$. When the probability of having a sale is zero, the number of sale products is:

$$
n_{1 j}=\left(\frac{\left(n_{j}\left(\alpha_{j} / m\right)-n_{2 j}\left(\alpha_{j} / m+\left(1-\alpha_{j}\right)\right)\right)\left(v_{h, j}-c_{j}\right)}{\left(\alpha_{j} / m+\left(1-\alpha_{j}\right)\right)\left(p_{j}-c_{j}\right)}\right) .
$$

So the number of sale products is expected to rise in the total number of products in the category, the proportion of high-valuation consumers and the depth of the promotion, but is inversely related to the margin earned on promoted items. This result - that the number of sale products rises with the proportion of high-valuation consumers - is opposite to Raju, Srinivasan and Lal (1990) who argue that the likelihood of promoting a single product is lower for products with stronger brand loyalty. More importantly, however, note that the number of promoted products and the depth of the promotion are directly related, meaning that depth and breadth are complementary tools as opposed to substitutes as is more commonly assumed to be the case (Banks and Moorthy 1999). Further, because retailers compete for shoppers on the basis of the average cost of their entire basket of goods, it is clear that th intensity of competitive behavior will be reflected in both the breadth and depth of the equilibrium promotional strategy.

Differentiating (8) with respect to the equilibrium price shows that the number of sale products falls as the sale price rises. Because non-loyal consumers buy their entire basket from the store that offers the lowest-cost set of sale goods, prices at rival retailers are implicitly strategic complements, or: $\partial p_{j} / \partial p_{-j}>0$. In other words, a price increase by a rival will cause a retailer to raise its own price, which in turn leads to a reduction in the number of sale products. This illustrates the fundamental complementarity between the depth of a promotion and the number of promoted products - if the promotional price is reduced during a sale, then a competitive retailer must offer more products at the sale price to maintain a given level of profit. This result also explains the co-existence of HI-LO and EDLP stores in the same market - firms either promote several products relatively heavily on a regular basis, or none at all. Not promoting is also consistent with a relatively low everyday price, just as equation (8) suggests. Further, this result has important implications for how retailers manage loss leaders. Rather than use one or two products to attract 
new customers, retailers tend to use a variety of products with dramatic discounts in order to convey the impression that the store has generally low prices. The importance of loss-leadership in this model suggests that the equilibrium promotion depth is another key metric of promotion intensity that arises from this model.

Following the logic used in finding (8) above, the equilibrium "magnitude" of the sale, or the depth of the promotion, is found by solving for the ratio of non-sale to sale margins at the lower support level of the sale price distribution:

$$
\frac{v_{h j}-c_{j}}{p_{j}-c_{j}}=\left(\frac{n_{1}\left(\alpha_{j} / m+\left(1-\alpha_{j}\right)\right)}{n\left(\alpha_{j} / m\right)-n_{2}\left(\alpha_{j} / m+\left(1-\alpha_{j}\right)\right)}\right) .
$$

Complementarity between depth and breadth is evident here as well. A retailer will reduce prices further the more products are on sale relative to the entire size of the category. If loss-leaders are offered, then HI-LO retailers will tend to use more of them than, of course, retailers following an EDLP strategy. Because this is an equilibrium model of sales, it also suggests that there will be a high correlation among stores offering loss-leaders in a given market. In other words, we are not likely to observe a market in which only one store offers loss-leader products. Although (8) and (9) address questions of significant theoretical research interest, on a practical level industry members are likely to be interested in the demand impact of price promotions.

More specifically, much of the marketing research in this area focuses on differentiating between the impact of price promotion on: (1) volume or market share of a particular brand or variety and (2) overall store or category-level volume (Gupta 1988; Bell, Chiang and Padmanabhan 1999; Pauwels, Hanssens and Siddarth 2002; Chintagunta 2002). Given that the effect on share and consumer numbers are necessarily specified in a very simple way in the theoretical model, we develop a more general econometric model to test the impact of both tools (number of sale products and depth of discount) on product and store sales. Further, if the depth of a promotion is indeed relatively more important to store, as opposed to product-level sales, rival prices are likely to become more important at the store-level to the extent that they affect the perceived depth of a store's promotion. Clearly, however, the relative impact of price promotions on product or store-level sales is a critical empirical question - one that is addressed in the next section. 


\section{Econometric Model of Price Promotion}

Whereas other empirical tests of theoretical price-dispersion models seek to explain the probability that a single product is offered for sale (Villas-Boas 1995, Pesendorfer 2002), this is clearly less relevant in a multi-product context where at least one product is offered on promotion at all times. Further, models of promotion effectiveness typically estimate only the demand side of the retail pricing problem and do not recognize the endogeneity of prices and the number of products offered for sale. Consequently, this paper adopts a structural approach to estimating the supply and demand for perishable products sold on promotion (Chintagunta 2002; Cotterill, Putsis and Dhar 2000; Besanko, Gupta and Jain 1998; Berry, Levinsohn and Pakes 1995). With this approach, equations describing optimal pricing rules are typically derived from the first order conditions for profit maximization and then estimated simultaneously with a demand system. Simultaneous estimation is necessary because profit maximization implies a set of cross-equation restrictions between optimal pricing rules and the demand equations. In the current example, however, equilibrium prices and the number of products offered for sale are described by (8) and (9) above, so we estimate these equations along with a general product-level demand system. In this way, the empirical model is able to: (1) test among alternative hypotheses regarding the number of products offered on sale during any given period (breadth of a promotion), (2) test hypotheses regarding the size of retail promotions (depth), and (3) determine the relative impact of promotional depth and breadth on individual product and category volume.

Conceptually, the econometric model consists of three sets of structural equations, based on the theoretical model of retail competition outlined above. Each of these sets of equations are explained in greater detail below, but are summarized here. The first consists of a discrete, count-data regression in which the number of products on promotion across all product categories at each retail chain is a function of own- and rivalmeasures of the depth of a promotion, the retail-wholesale margin, the total number of products sold, and retailing costs. Second, pricing decisions are defined in terms of the depth of promotion offered each week on a representative "sale" product. Promotional depth is measured as the difference between the price in the previous week and the price in the current week of a representative product from each category. This approach is necessary because using an "average sale magnitude" over all products would obscure the difference between normal price variation and a true price promotion. Further, because this representative 
product is not discounted each period, the model of promotion depth is estimated as a Tobit, or censoredregression model. Promotional depth is hypothesized to depend on the number of products offered on sale, the number of products offered in total, the average margin earned on non-sale products, rival measures of promotional intensity, and retailing costs. In order to account for the simultaneous nature of pricing, sales breadth and demand, fitted values from each of the first two models are substituted into a general twolevel model of retail demand. Specifically, the demand model includes both lower-level, individual product demands (intra-store) as well as upper-level, product category demands (inter-store) in order to separate product-specific from overall store effects (Hausman 1997). In this way, the empirical procedure accounts for both individual product as well as inter-category and inter-store, or competitive, effects of a price promotion.

In the first stage, hypotheses regarding the determinants of the number of products offered for sale each week by each chain in each market are tested. Because the number of sale products, $n_{1 j}$, is a multi-variate discrete variable, it is necessary to use an approach that explicitly accounts for the count-data nature of the dependent variable. More formally, the number of products on promotion during a given week are assumed to arrive according to a Poisson process, which is written in general form:

$$
\operatorname{Pr}\left[n_{1 j t}=k_{j t}\right]=\frac{\lambda^{k_{j t}} e^{-\lambda}}{k_{j t} !}, k_{j t}=0,1,2, \ldots
$$

where $n_{1 j t}$ is the number of products offered on promotion in week $t$ by store $j$, and $\lambda$ is the average number of products offered for sale during a typical week. Within this general framework, hypotheses regarding the the number of sale products offered by retailer $j$ are tested by allowing $\lambda$ to vary with a vector of explanatory variables, $\mathbf{Z}_{j}$, according to:

$$
\ln \lambda_{j}=\beta^{\prime} \mathbf{Z}_{j}+\varepsilon_{j t}
$$

where $\mathbf{Z}_{j}$ is a vector of factors in the structural model outlined above, namely the total number of products sold by retailer $j$, the change in sales from the previous non-sale period, an estimate of the average margin obtained on sale products, the depth of the discounts offered, the number of products offered for sale and in total by rivals, and rival margins. Because each of these variables is endogenous to the $j$ retailer's decision, lagged values of each are used as instruments. Moreover, the Poisson model is often criticized for 
implicitly assuming that the conditional mean and variance are equal. In practice, researchers typically reject this maintained hypothesis, finding instead that the variance is greater than the mean - a condition called "overdispersion." Overdispersion leads to inconsistent estimates of the entire parameter vector. Consequently, generalizations of the basic model take this into account, wherein the distribution of $\varepsilon_{j t}$ determines the specific form of the alternative model. Specifically, if $g\left(\varepsilon_{j t}\right)$ is gamma distributed, then $n_{1 j t}$ follows a negative binomial distribution with density:

$$
f\left(n_{1 j t}\right)=\left(\frac{1}{\Gamma\left(\nu_{j t}\right)}\right)\left(\frac{\nu_{j t} n_{1 j t}}{\psi_{j t}}\right)^{v_{j t}} \exp \left(\frac{-\nu_{j t} n_{1 j t}}{\psi_{j t}}\right) \frac{1}{\psi_{j t}}
$$

where $\psi_{j t}$ is the mean of the process, $\nu_{j t}$ is the precision parameter, and $\Gamma$ is the gamma density function (Cameron and Trivedi 1986). Cameron and Trivedi (1986) develop a simple regression-based test for overdispersion that is useful in selecting between a Poisson and the more general negative binomial models. Under the null hypothesis of no overdispersion, the variance of $n_{1 j t}$ is equal to its mean, but under the alternative, the variance is some function of the mean:

$$
\begin{aligned}
& H_{0}: V\left[n_{1 j t}\right]=\psi_{j t} \\
& H_{1}: V\left[n_{1 j t}\right]=\psi_{j t}+\gamma h\left(\psi_{j t}\right),
\end{aligned}
$$

where they assume simple linear or quadratic functional forms for $h\left(\psi_{j t}\right)$. With either of these assumptions, testing for overdispersion then involves running linear regressions of the variance of $n_{1 j t}$ on each $h\left(\psi_{j t}\right)$ and conducting t-tests for the significance of $\gamma$. If this parameter is significantly different from zero, the Poisson specification is rejected in favor of the negative binomial. Once this model is estimated, fitted values of $n_{1 j t}$ are then used in a second-stage model of retailer pricing behavior.

The second model describes the equilibrium pricing rules followed by each retailer, or the amount by which they choose to discount sale products. In single-product models of retail promotion, the magnitude of a discount and its probability are typically regarded as simultaneous decisions (Lal and Villas-Boas 1998; Jeuland and Narasimhan 1985). In a multi-product context, however, equation (9) shows that the depth of a promotion is related to the proportion of a store's products offered for sale, as well as competitive factors 
that describe the relative costs and benefits of promoting each product. To test the individual effect of each factor on promotional depth, we specify this structural equation in a manner amenable to estimation on a product-level basis. However, because each store typically offers many sale products on any given week, it is not possible nor necessary to explain the price of each product offered on sale. Rather, one product is chosen as a "representative sale product" from within each sub-category (ie. apples, grapes and oranges) and the depth of its discount is estimated as a function of the vector $\mathbf{X}_{j}$ and the size of the promotion offered on similar products in rival stores. In this way, the model accounts for any potential substitute or complementary relationships both within and among stores.

By definition, however, the dependent variable in this model is not continuous. In fact, the variable measuring promotional depth is usually zero, but is non-zero during sale periods. Because each dependent variable is censored at zero, the sale-depth model is estimated as a set of simultaneous Tobit models - one equation representing the promotion of each representative product. Defining the depth of a promotion for product $i=1,2, \ldots n_{1 j}$ offered by store $j=1,2, \ldots m$ as $d_{i j}=\left(v_{h, i j}-p_{i j}\right)$, the set of Tobit equations is written:

$$
d_{i j}^{*}=\sum_{-i \in-n_{1}} \gamma_{i j} d_{-i j}+\sum_{-j \in-m} \gamma_{-j i} d_{-j i}+\sum_{k \in K} \alpha_{k} X_{k}+\varepsilon_{2 i j}, d_{i j}=\max \left[0, d_{i j}^{*}\right]
$$

for all $m$ stores and representative sale products. Following the theoretical model above, equation (9) suggests that the vector $\mathbf{X}_{j}$ consists of the ratio of the total number of individual SKUs in each category, $n_{j}$, to total sale products, $n_{1 j}$, the average margin earned on sale-products, $\left(p_{i j}-c_{i j}\right)$, proxies for total store traffic, which are defined as reference product volume, $q_{i j}$, and the incremental sales volume during promotion weeks for the sale product $q_{i j}^{1}-q_{i j}^{0}$, as well as rival price, margin and product-count variables. As in the previous model, lagged values for all endogenous explanatory variables are used to avoid collinearity between equation errors and the dependent variable. Further, fitted values from the discount model serve as instruments for endogenous promotion variables in the demand model, which is described next.

A third econometric model estimates the impact of each of these measures of "promotion intensity" the number of products offered on sale and the depth of promotion - on individual product and category volume. In doing so, we explicitly recognize that each of these outcomes is determined simultaneously. As such, it would clearly be preferable to estimate all three stages together in one model. However, given 
the inherent complexity of the retail-sales decision framework, there is econometric approach that can deal with the non-standard structure of each component in a consistent, simultaneous way. Consequently, fitted values of the Poisson intensity parameter from the first stage and fitted promotional-depth values from the second-stage Tobit model are used as instrumental variables in the retail demand model.

If perishable products are offered for sale as loss-leaders, it is expected that their impact will be felt in two ways: (1) directly on own-product sales volume, and (2) indirectly on category volume. In order to increase store profitability, however, it is necessary that a promotion not only cause consumers to reallocate spending among products in a given cateogory, but to expand total category volume. Consequently, the demand model accounts for both individual product and category choice effects. To do so, the model is specified in terms of a two-level demand system, which is consistent with both consumer budget-allocation behavior and endogeneity of the promotion decision (Hausman 1997).

In a two-level demand system, the lower-level consists of individual product choice, or budget share equations $\left(w_{i}\right)$, within a given product category, while the upper-level equations $\left(Q_{j}\right)$ consist of category choice equations. However, given the effect of price-promotions outlined above, namely as loss-leaders within a multi-product, imperfectly competitive environment, here we model the upper-level equations as describing consumers' choice among stores, not product categories. At the lower-level, on the other hand, the empirical model estimates the extent to which consumers substitute among different products once attracted to a particular store. Consequently, the upper-level equations here consist of the sales of each store relative to others in a particular market. ${ }^{2}$ Taken together, the response model forms a theoretically consistent two-level demand system with strategic elements. Theoretical consistency in this context means that the demand system describes budget allocation within one branch of an $S$-branch utility tree in a way that adheres to the restrictions implied by constrained consumer utility maximization (Brown and Heien 1972; Anderson 1979).

Specifically, at the lower-level, the demand system consists of six share equations, representing the three sale products and "all others" within each fruit subcategory, while the upper-level consists of a single equation

\footnotetext{
${ }^{2}$ While we refer to store-level data and decisions to remain comparable to common usage in the literature, the econometric analysis is more correctly conducted at the chain-level within each market. Price points are homogeneous across all stores in each market for each chain.
} 
representing all fresh fruit sales. Selection of the forms of this two-level system is constrained by the requirement that either: (1) the upper-level (among category allocation) is weakly separable and the lowerlevel (within category allocation) is homothetic-separable, or (2) the upper-level is additive (block) separable and the lower-level is of general form (Anderson 1979). Because the restriction of homothetic-separability on the individual product demands is unrealistic, we choose the latter and specify the upper-level demand equation as a linear-expenditure system (LES) and the lower-level demands as a linear-approximate Almost Ideal Demand System (LAIDS).

In addition, this model also accounts for the simultaneity of sales-response, the decision to promote products within each category and the depth of the promotion. To accomplish this in a straightforward way, a generalized Heckman approach is used wherein index values for each of the discrete variables in the prior stages are substituted into the third-stage model prior to estimation. As such, this method is similar to the class of simultaneous equations models with discrete / continuous selectivity developed by Lee, Maddala and Trost (1980). Given each of these considerations, the LES upper-level demands are written:

$$
X_{j}=P_{j} Q_{j}=\Theta_{j 1} P_{j}+\Theta_{j 2}\left(\left(Y-\sum_{r \in R} P_{r} Q_{r}\right)+\sum_{j \in m} \Theta_{j 3} \hat{D}_{j}+\sum_{j \in m} \Theta_{j 4} \hat{n}_{1 j}+\sum_{s \in S} \Theta_{s 5} M_{s}+\mu_{1},\right)
$$

while the LAIDS, lower-level demands are given as:

$$
w_{i j}=p_{i j} q_{i j} / X_{j}=\theta_{i j 0}+\sum_{l} \theta_{i j l 1} \ln p_{i j 1}+\sum_{k} \theta_{i j k 2} \ln \left(\frac{X_{j}}{P_{j}}\right)+\theta_{i j 3} \hat{d}_{i j}+\theta_{i j 4} \hat{n}_{1 i j}+\sum_{t} \theta_{i j 5} M_{i j t}+\mu_{i j 2},
$$

where $\mu_{1}$ and $\mu_{i j 2}$ are iid normal error terms, $j$ indexes a particular store, $r$ indexes all stores in a given market, $D_{j}$ is the average markdown among sale products in store $j, Y$ is total consumer income, $X_{j}$ is total fruit expenditure within store $j, \hat{n}_{1 j}$ is the number of sale products offered by store $j$, and $M_{j}$ is a set of store-demand variables that includes the number of products offered on promotion by rival stores, the total number of products stocked by rivals, rival price, margins and discount levels. At the lower-level, $w_{i j}$ is the store-expenditure share of each product, $p_{i j}$ is the shelf-price of each product $i$ in store $j, \hat{d}_{j k}$ is the depth of promotion for each representative sale item, $\hat{n}_{1 i j}$ is the total number of products in category $i$ offered on promotion in store $j$, and $M_{j t}$ is a set of $t$ store-level demand variables that includes the total 
number of products in category $i$, as well as the the number of products stocked and promoted by rivals. Products in this model are defined to include a "sale" and "non-sale" aggregate within each fruit type in order to estimate the effect of a promotion on sales of the promoted product and the category as a whole. While the definition of a "sale" product is provided in more detail below, the "non-sale" aggregate consists of all product codes of each type of fruit that are not chosen as the representative, or sale item. Non-sale prices, therefore, are indices calculated across all products within a particular category other than the one that is being promoted. Because the size of the discount and the number of products offered on promotion are endogenous, instruments for each variable are created by calculating the Poisson and Tobit indices, respectively, from equations (12) and (15) above and substituting them into (16) and (17):

$$
\begin{aligned}
& \hat{d}_{j i}=\max \left[0, d_{j k}^{*}\right], \hat{D}_{j}=\sum_{k} \hat{d}_{j k} / K_{j}, \\
& \hat{n}_{1 j}=E\left[\hat{n}_{1 j}\right]=\hat{\lambda}_{j},
\end{aligned}
$$

By accounting for the simultaneity of each decision in this way all parameter estimates will be consistent, but not as efficient as they would be if they were all estimated in one step. Due to the complexity of the empirical model, however, doing so is not feasible. Further, note that in the LAIDS model, ln $P_{j}$ is a Stone price index calculated as: $\ln P_{j}=\sum_{i} w_{i j} \ln p_{i}$ for all $j=1,2, \ldots m$ stores. At the lower-level the restrictions of symmetry and homogeneity are tested and imposed with the following parameter restrictions:

$$
\sum_{i} \theta_{i 0}=1, \sum_{i} \theta_{i l 1}=0, \sum_{i} \theta_{i 3}=0, \sum_{l} \theta_{i l 1}=0
$$

As is well known, however, the LAIDS parameters lack a direct interpretation, so price elasticities are calculated as:

$$
\varepsilon_{i 1}=-\delta_{i}+\left(\theta_{i l 1}+\theta_{i 3} w_{i}\right) / w_{l}
$$

while the expenditure elasticity for each store is:

$$
\eta_{i}=-1+\theta_{i 3} / w_{i}, \forall i=1,2, \ldots n
$$


where $\delta_{i}$ is Kronecker's delta and all other parameters are defined in (17).

At the upper-level, own-price elasticities provide a measure of market power for each store, while the cross-price elasticities are interpreted as strategic response parameters. In terms of the parameters of (16), the LES own-price elasticities are written:

$$
\Omega_{j j}=-1+\left(1-\Theta_{j 2}\right) \Theta_{j 1} / Q_{j}
$$

while the cross-price elasticities are:

$$
\Omega_{-j j}=-\Theta_{j 2}\left(P_{-j} \Theta_{-j 1} / P_{j} Q_{j}\right.
$$

for rival stores in the same market, indexed by $-j$. Own and cross-elasticities can also be defined for the promotion magnitude and number of sale products in an obvious way. Estimating this entire set of equations is only possible with a broad, panel data set of high-frequency scanner data, which are described more fully in the next section.

\section{$5 \quad$ Data and Methods}

The data for this study consist of two years of weekly store-level scanner data for a variety of fresh fruits supplied by Fresh Look Marketing, Inc. of Chicago, IL. Product-level (UPC or PLU code) price and quantity data are provided for each chain in six regional markets, for a total of 20 cross-sectional observations, each of 104 weeks in length. Because of the volume of individual product codes involved, the sample consists of a representative group of high-volume products within the fresh fruit category. Although the data describe all varieties of fresh apple, navel and valencia oranges, and all varieties of table grape, we capture the multiproduct nature of produce retailing while maintaining analytical tractability by defining one "sale product" and an aggregate "all other" from each category - apples, grapes and oranges. However, stores vary in their offerings and product descriptions, so it is not possible to define one standard product from each category across all chains and markets. Rather, the sale product is defined according to the following criteria: (1) the 
product must be offered in all 104 weeks of the sample, (2) it must be among the top three products within the category in sales volume, (3) its price must change at least twice by at least $10 \%$ on a week-to-week basis, and (4) if a bulk (bagged) product is chosen to represent one chain in a particular market, then an equivalent bulk (bagged) product is chosen from other chains in the same market. Defined this way, each sale product represents a key category-driver in each store and a transparent point of reference for both consumers and all competing stores in the same market. For each sale product, a price promotion is defined as a reduction in price greater than or equal to $10 \%$ from the previous week's average selling price. Alternative definitions of $5 \%$ and $15 \%$ were considered, but the results did not differ appreciably from those reported here. The "number of sale products" variable is calculated by counting all PLUs with shelf prices at least $10 \%$ below their level in the previous week. For each category, the "all other" price index is a value-weighted average of all PLUs that are not the sale product, while the "all other" quantity variable is a simple volume sum. All rival prices are also calculated as value-weighted averages for the same PLU in all other stores in the same market. All prices and quantities are expressed in dollars per pound and pound-equivalents where bagged products are sold.

In addition to variables that can be calculated from the scanner data - such as the number of products on sale, the total number of different products offered to consumers, the average depth of promotion or rival activities, the average margin and the change in category sales - each model contains a set of exogenous factors that may otherwise influence the decision in question. Exogenous variables in the first-stage, countdata model include estimates of the average margin for each product and retailer as well as a retailing cost index. Margins are calculated as the shelf price less the prevailing wholesale price for the appropriate week. Wholesale prices, in turn, are obtained from either the Washington Growers Clearing House (apples) or NASS-USDA (grapes and oranges) and represent average FOB shipping-point prices across all sizes and grades. As such, these prices do not exactly represent the variety of products offered at retail, but changes in a representative FOB price will be highly correlated with changes in any wholesale price defined in a more specific way. Retailing input prices include an index of wages paid in the food-retail sector and are obtained from the Bureau of Labor Statistics on a monthly basis. All variables are left in nominal, rather than real, terms. With these data, the empirical models described above are estimated in three-stages 
using maximum likelihood. The final-stage standard errors are corrected for the induced heteroskedasticity inherent in this estimation procedure in the usual way (Greene 2001). Table 1 summarizes all of the data used in this analysis.

\section{$6 \quad$ Results and Implications}

Prior to testing the central hypotheses of the paper, a series of specification tests are conducted to ensure that each model is appropriate to the problem at hand. This section presents the results from applying tests specific to each of the three models: (1) a count-data model for the number of sale products, (2) a Tobit model for retailers' equilibrium pricing decisions, and (3) a two-level LES / LAIDS model to determine the relative impact of price discounts and the number of products on promotion. Ultimately, the results are used to compare the relative effectiveness of the depth of promotions versus their breadth.

In the first-stage, the question is whether a Poisson model or Negative Binomial model is preferred. Selecting between these two alternatives depends upon whether there is evidence of overdispersion in the data. If so, then a Negative Binomial is appropriate. The regression-based specification test of Cameron an Trivedi (1986) involves regressing the Poisson variance against the squared-mean. A t-test finds that the resulting regression parameter, $\mathbf{\square}$ in table 2 , is significantly different from zero at a $5 \%$ level of significance for each product-model. Consequently, the remaining results in table 2 are found using a Negative Binomial model. As equation (9) indicates, the number of sale products is expected to rise with the total number of products in the category and in the size of the discount, but fall in the retail-wholesale margin. After controlling for several measures of retailing cost, it is clear from these results that promotional breadth and depth are indeed complementary, as expected. Specifically, the larger the discount offered on any individual product, the more products need to be offered on sale in order to maintain a constant level of profit. This result is somewhat counter-intuitive as it suggests that retailers cannot make up for maintaining few sale items by offering a small number of loss-leaders. Rather, similar to Banks and Moorthy (1999), a retailer either adopts a HI-LO strategy and attempts to win all of the low-valuation consumer business, or adheres to an EDLP or an EDHP (everyday-high-price) strategy and does not compete for the other market segment. Second, the number of sale products falls in the average margin. Intuitively, if a retailer "buys" 
low-valuation consumers by taking a lower margin on high-valuation consumers, they will offer fewer sale products the less incremental profit they expect to earn from the low-valuation segment. Further, a retailer can expect to earn less on complementary impulse-buy products, so will offer fewer products the lower the margin he expects to earn. Third, if a retailer expects a promotion to be successful, then the number of sale products rises with expected category sales. Clearly, if sales are intended to build traffic through the store, a promise of success will cause the retailer to promote more aggressively. However, this measure is only a proxy for category volume as it combines both the number of consumers and individual purchase volume. Fourth, the more different types of products (stock keeping units, or SKUs) sold by a retailer, the more it will offer on promotion at any given time. This result is intuitive because a retailer would have to offer a similar proportion of goods on sale to maintain a perception of promoting as aggressively as a rival with fewer SKUs in total. It is also similar to Dixit and Stiglitz (1977) in that product-variety represents an important equilibrium outcome in addition to per-product output and retail price.

A fifth set of variables measures the strength of competitive reaction in terms of both prices and number of sale products. These variables can be thought of as measuring the degree of loyalty to a particular store as loyalty only has meaning relative to the strength or weakness of competitive interaction. If rival stores follow relatively high-price strategies, then there is less pressure for a retailer to promote aggressively. The results in table 2 show that this is generally the case, although the parameter estimates are not significant for all products. Moreover, it is expected that more sale products and total products offered by rivals will induce a like reaction from each store. However, the estimates find that retailers rather adopt an accommodation or "puppy dog" strategy and reduce sale offerings in the face of aggressive promotion by rivals. This result is similar to that predicted by Narasimhan (1988) who suggests that retailers with larger loyal segments tend to promote less frequently and with smaller discounts. If a retailer does enjoy a large loyal market segment, then he need not sacrifice profit in order to maintain share in the face of a rival's frequent promotions. Retailers do, however, increase the number of products offered for sale the greater the number of total products offered by rivals. Again, this result provides evidence that variety, as measured by the number of products offered for sale, is an element of any monopolistically competitive equilibrium among retail supermarkets in the sense of Dixit and Stiglitz (1977). The complementary role of discounting, 
however, is unique to this study.

[table 2 in here ]

Table 3 presents several goodness-of-fit measures for each Tobit model. Both the likelihood ratio chisquare statistic and the F-statistic of the overall model suggest that each model is preferred to a null alternative. As these are, however, only weak tests, this table also offers a more direct test of the Tobit specification. Namely, if the Tobit "normalizing" parameter, $\alpha$, is significantly different from zero, then the non-censored alternative is rejected. Given that the Tobit is appropriate for these data, table 3 also presents the normalized MLE coefficients used to test each hypothesis regarding promotional depth. Based on the theoretical model given in (8), the magnitude of any given promotion, or the depth of the discount, will be negatively related to the total number of products displayed, the expected incremental gains from the promotion and the proportion of high-valuation consumers. On the other hand, the size of any discount is expected to rise in the number of sale products and the margin earned on them.

For each product, the complementarity between promotional breadth and depth appears to be the most important factor in determining the size of a discount. Retailers appear to recognize the fact that capturing market share requires a greater investment the more intense the competition for critical market segments. Further, the results in table 3 also support the hypothesized effect of total category size on promotional intensity. For each product, the size of the discount falls the more total products are offered, which suggests that variety and promotion are competitive substitutes rather than complements. Although the evidence is less clear, firms that earn higher margins also promote more intensely than others. According to the estimates in table 3, HI-LO retailers use higher margins, on average, to justify their use of deep promotions on loss-leaders as a means of increasing store traffic. Retailers also tend to reduce discounts if they expected greater gains in category sales. Although promotional response to rival behavior tends to be statistically weaker, it is nonetheless generally significant. Specifically, retailers raise discounts the greater the variety offered by competitors, but reduce discounts as rivals raise the number of products on sale. As before, this result can be interpreted as an accomodative, or "puppy dog" strategy wherein aggressive behavior by a rival elicits a passive response in reply. If rivals charge relatively high margins, retailers in the same market appear to discount more heavily, suggesting that there are more rents in the market to be gained through 
a successful promotion. Although discounts and sale-product numbers are complementary, the theoretical model does not suggest which should be more effective in increasing share or total category sales. .

[table 3 in here]

To explore this issue, the third estimation stage consists of one market-level LES equation that captures any potential store-level demand expansion effects, and five product-level LAIDS expenditure-share equations. ${ }^{3}$ According to the goodness-of-fit statistics in table 4, the LES regression is highly significant and explains much of the variation in store-level sales. In this table, all results are expressed as elasticities, so suggest that fruit category sales for an individual store are quite inelastic and only weakly responsive to prices in other stores in the same market, although the effect is highly statistically significant. More important for purposes of this paper, however, store sales rise significantly in both the number of products offered on sale and the size of the associated discount. In terms of their relative elasticity values, promotional breadth appears more effective than depth in generating traffic. Thus, loss-leadership may not, in fact, be optimal. Instead, given the complementary effects of breadth and depth, a store may be better off by offering a broad array of products on sale, but not necessarily taking a loss on each. Because few consumers actually recall what constitutes a "normal" shelf price, the announcement effect of crowding a food-page ad with many different sale products may indeed be an effective strategy. Whereas the first two, product-level stages of the analysis - the number of sale products and the size of discount - suggest that inter-store rivalry in produce marketing is not likey to be nearly as important as own-discount and sale strategies, rivarly appears to be far more significant at the store-level. Measured in terms of category-averages, prices between retailers in the same market appear to be statistically significant, yet somewhat small, strategic-substitutes. This result is consistent with industry observations that retailers, despite relatively high local market shares, tend to face aggressive competition from not only supermarkets, but a host of other retail food store formats. At this level of analysis, however, it is difficult to tell whether incremental volume is due to selling more loss-leader products or if store traffic has indeed increased.

[table 4 in here]

By dividing each product into "sale" and "non-sale" sub-groups, the model is able to determine whether

\footnotetext{
${ }^{3}$ Hausman (1997) employs a similar approach in estimating the share and category effects of introducing new cereal brands.
} 
any positive effect on volume results from selling more discounted products or if demand for all products has risen. If discounts only serve to increase promoted product-share, then the higher store volumes found in the market-level LES model will not likely lead to higher profit. In fact, the elasticity estimates in table 5 show that price discounts exhibit a nearly uniform pattern of increasing loss-leader share at the expense of higher margin, non-sale items. However, increasing the number of products on sale has the opposite effect of increasing high-margin product sales. Although breadth and depth have complementary effects on sales, in this econometric framework the synergistic effect is already included in the first-stage LES model, so that the lower-level share model provides independent, or partial estimates of the effect of each tool on its own. With this in mind, the results in table 5 indicate that increasing promotional breadth may be preferable to investing in fewer, loss-leader products. Further, the price elasticities reported in table 5 indicate that nearly all products are in the vicinity of unit-elasticity. Therefore, it is not obvious that price reductions will either increase or decrease total revenue for the promoted product. Neither does it appear to be the

case that there is sufficient demand complementarity for loss-leaders to be effective in the sense of Bliss (1988) in increasing overall store profitability, although oranges and grapes do appear to be relatively strong complements. In general, however, these results appear to challenge the standard loss-leader orthodoxy in favor of more broad-based, yet shallower promotional strategies.

[table 5 in here]

\section{Conclusions}

This paper seeks to both explain the frequency and depth of price promotions - sales - of perishable food products by supermarkets and determine their relative impact on individual product share and overall category demand. A theoretical model of industry equilibrium under monopolistic competition shows that price promotions are mixed strategy equilibria in a dynamic, multi-product environment with heterogenous consumers. The conceptual model of price promotions suggests suggests several testable hypotheses regarding: (1) the number of products offered on promotion at any given time, (2) the depth of price discount offered, and (3) the relative impact of each on store- and category sales volume. Most importantly, and contrary to popular belief, promotional breadth (number of products offered for sale) and depth (the magnitude of the 
discount) are complementary tools in increasing demand, rather than substitutes.

By recognizing the endogeneity of promotional prices and number of products offered on promotion, we develop an empirical model of the equilibrium between the supply and demand for perishable products at the retail level. Within this framework, the breadth of promotion across the product line is estimated with a Negative Binomial count-data model, while promotional depth is estimated using a Tobit model. Fitted values of both sale-product numbers and discount-magnitude are used as instruments in a theoretically consistent two-level demand system framework designed to test the effect of each on product-share and overall category demand. The data consist of two-years of weekly, store-level retail scanner price and quantity observations for the fresh fruit category (apples, grapes and oranges) for six major U.S. markets. Estimates of all three model components with these data provide evidence in support of the complementary relationship between promotional depth and breadth, but show that offering more products on sale at any given time is likely to be more effective in generating demand compared to relying on a few loss-leaders in each category. There is also considerable evidence that price-promotions are effective tools for strategic interaction, but overall price levels are the dominant factor in determining overall market share.

The implications of this research reach beyond the fresh fruit data that are used here. First, by estimating a more general model of price promotion that nests competing explanations such as pure rivalry, cost variation or price discrimination, this study provides guidance for future theoretical research that has tended to draw increasingly narrow assumptions regarding the cause of retail sales. Second, the empirical results show that the primary effects of offering a sale for perishable goods, both in terms of the number of promoted products and the size of the discount, are stronger than previously believed to be the case. Marketing managers, therefore, may find justification in using aggressive pricing tactics in conjunction with their category management programs. Third, existing empirical approaches to testing theories of price promotions in the industrial organization literature, or the effectiveness of promotions in the empirical marketing literature, must recognize that the usual explanatory variables in both are jointly endogenous so must be estimated as such.

Future theoretical research in this area would benefit from pursuing a more general approach than that offered here. While this research explains the existence of promotions among an important class of products, 
it may not be appropriate for others. However, this paper shows that promotional breadth - a tool that had previously been ignored - does play an important role in food marketing strategy, so may for other products as well. Second, future empirical research may consider a broader selection of perishable products from categories other than fresh fruit. Allowing for a more general pattern of cross-category substitution may provide valuable information regarding the impact of sales on other categories in the store, thereby offering a more direct test of the loss-leader hypothesis. 


\section{References}

Aguirregabiria, V. 1999. "The Dynamics of Markups and Inventories in Retail Firms." Review of Economic Studies 66: 275-308.

Anderson, R. W. 1979. "Perfect Price Aggregation and Demand Analysis." Econometrica. 47: 1209-1230.

Arnold, S., T. Oum, and D. Tigert. 1983. "Determinant Attributes in Retail Patronage: Seasonal, Temporal, Regional and International Comparisons." Journal of Marketing Research 20: 149-157.

Bass, F. M. 1980. "The Relationship Between Diffusion Rates, Experience Curves and Demand Elasticities for Consumer Durable Technological Innovations." Journal of Business 53: S51-S67.

Bell, D., J. Chiang, and V. Padmanabhan. 1999. "The Decomposition of Promotion Response: An Empirical Generalization." Marketing Science 18: 504-526.

Bell, D. R., G. Iyer, and V. Padmanabhan. 2002. "Price Competition Under Stockpiling and Flexible Consumption." Journal of Marketing Research 39: 292-303.

Berry, S. T. 1994. "Estimating Discrete Choice Models of Product Differentiation." RAND Journal of Economics 25: 242-262.

Levinsoh, J. and A. Pakes. 1995. "Automobile Prices in Market Equilibrium." Econometrica

63: $841-890$.

Besanko, D., S. Gupta and D. Jain. 1998. "Logit Demand Estimation under Competitive Pricing Behavior: An Equilibrium Framework." Management Science. 44: 1533-1547.

Blattberg, R., G. Eppen, and J. Lieberman. 1981. "A Theoretical and Empirical Evaluation of Price Deals for Consumer Non-Durables." Journal of Marketing 45: 116-129.

Blattberg, R. G. and A. Levin. 1987. "Modeling the Effectiveness and Profitability of Trade Promotions." Marketing Science 6: 124-146.

Bliss, C. 1988. "A Theory of Retail Pricing." Journal of Industrial Economics 36: 375-390.

Boizot, C., J. M. Robin and M. Visser, 2001. "The Demand for Food Products: An Analysis of Interpurchase Times and Purchased Quantities." Economic Journal 111: 391-419.

Brown, M., and D. Heien. 1972. "The S - Branch Utility Tree: A Generalization of the Linear Expenditure System." Econometrica 40: 737-47. 
Burdett, K. and K. L. Judd. 1983. "Equilibrium Price Dispersion.” Econometrica 51: 955-969.

Butters, G. R. 1977. "Equilibrium Distributions of Sales and Advertising Prices." Review of Economic Studies 44: 465-491.

Cameron, A.C. and P.K. Trivedi. 1986. "Econometric Models Based on Count Data: Comparisons and Applications of Some Estimators and Tests." Journal of Applied Econometrics 1:29-53.

Chintagunta, P. K. 2002. "Investigating Category Pricing Behavior at a Retail Chain." Journal of Marketing Research 39: 141-154.

Cotterill, R. W., W. P. Putsis, Jr., and R. Dhar. 2000. "Assessing the Competitive Interaction Between Private Labels and National Brands." Journal of Business 73:109-137.

Dixit, A. and J. Stiglitz. 1977. "Monopolistic Competition and Optimum Product Diversity." American Economic Review 67: 297-308.

Dreze, X. 1995. "Loss Leaders: Store Traffic and Cherry Picking." unpublished Ph.D. disstertation. University of Chicago, Chicago, Ill.

Epstein, G. S. 1998. "Retail Pricing and Clearance Sales: The Multiple Product Case." Journal of Economics and Business 50: 551-563.

Gerstner, E. and J. Hess. 1991. "A Theory of Channel Price Promotions." American Economic Review 81: $872-887$.

Giulietti, M. and M. Waterson. 1997. "Multiproduct Firms' Pricing Behaviour in the Italian Grocery Trade." Review of Industrial Organization 12: 817-32.

Green, E. and R. Porter. 1984. "Noncooperative Collusion Under Imperfect Price Information." Econometrica 52: 87-100.

Han, S., S. Gupta, and D. R. Lehmann. 2001. "Consumer Price Sensitivity and Price Thresholds." Journal of Retailing 77: 435-456.

Hausman, J. 1997. "Valuation of New Goods under Perfect and Imperfect Competition." in The Economics of New Goods, eds. T. F. Bresnahan and R. J. Gordon. National Bureau of Economic Research. Chicago, IL: University of Chicago Press.

Hess, J. D. and E. Gerstner. 1987. "Loss Leader Pricing and Rain Check Policy." Marketing Science 6: 
358-374.

Hosken, D., Reiffen, D. 2001. "Multiproduct Retailers and the Sale Phenomenon" Agribusiness: An International Journal 17: 115-137.

Jeuland, A. P. and C. Narasimhan. 1985. "Dealing - Temporary Price Cuts by Sellers as a Buyer Discrimination Mechanism." Journal of Business 58: 295-308.

Lal, R. 1990. "Pricing Promotions: Limiting Competitive Encroachment" Marketing Science 9: 247-262.

Lal, R. and M. Villas-Boas. 1998. "Price Promotions and Trade Deals with Multiproduct Retailers." Management Science 15: 935-49.

Landsberger, M., and I. Meilijson. 1985. "Intertemporal Price Discrimination and Sales Strategy Under Incomplete Information" Rand Journal of Economics 16: 414-440.

Lazear, E.P. 1986. "Retail Pricing and Clearance Sales." American Economic Review 76: 14-32.

Lee, L., G. S. Maddala, and R. P. Trost. 1980. "Asymptotic Covariance Matrices of Two Stage Probit and Two Stage Tobit Models for Simultaneous Equations Models with Selectivity." Econometrica 48: 491-504.

McAfee, R. 1995. "Multiproduct Equilibrium Price Dispersion." Journal of Economic Theory 67: 83-105. McMillan, J. and P. B. Morgan. 1988. "Price Dispersion, Price Flexibility and Repeated Purchasing." Canadian Journal of Economics 21: 883-902.

Mulhern, F.J. and R.P. Leone. 1991. "Implicit Price Bundling of Retail Products: a Multiproduct Approach to Maximizing Store Profitability." Journal of Marketing 55: 63-76.

Narasimhan, C. 1984. "A Price Discrimination Theory of Coupons." Marketing Science 3: 128-147.

Narasimhan, C. 1988. "Competitive Promotional Strategies." Journal of Business 61: 427-449.

Nijs, V. R., M. G. Dekimpe, J.-B. E. M. Steenkamp and D. M. Hanssens. 2001. "The Category Demand Effects of Price Promotions." Marketing Science 20: 1-22.

Pashigian, B. P. 1988. "Demand Uncertainty and Sales: A Study of Fashion and Markdown Pricing." American Economic Review 78: 936-953.

Pashigian, B. P. and B. Bowen. 1991. "Why are Products Sold on Sale? Explanations of Pricing Regularities" Quarterly Journal of Economics 106: 1015-1038.

Pauwels, K., D. M. Hanssens, and S. Siddarth. 2002. "The Long-Term Effects of Price Promotions on 
Category Incidence, Brand Choice and Purchase Quantity." Journal of Marketing Research 39: 421-439.

Pesendorfer, M. 2002. "Retail Sales: A Study of Pricing Behavior in Supermarkets." Journal of Business 75: 33-66.

Pratt, J. W., D. Wise, and R. Zeckhauser. 1979. "Price Differences in Almost Competitive Markets." Quarterly Journal of Economics 93: 189-211.

Produce Marketing Association. 2001. Fresh Tracks: Supply Chain Management in the Produce industry Food Industry Management Program, Cornell University, Ithaca, NY.

Raju, J. S., Srinivasan, V. and R. Lal. 1990. "The Effects of Brand Loyalty on Competitive Price Promotional Strategies." Management Science 16: 276-304.

Reinganum, J. 1979. "A Simple Model of Equilibrium Price Dispersion." Journal of Political Economy 87: $851-858$.

Rob, R. 1985. "Equilibrium Price Distributions." Review of Economic Studies 52: 487-504.

Rotemberg, J. and G. Saloner. 1986. "A Supergame-Theoretical Model of Business Cycles and Price Wars During Booms." American Economic Review 76: 390-407.

Rothschild, M. 1974. "A Two-armed Bandit Theory of Marketing Pricing." Journal of Economic Theory 9: $185-202$.

Shilony, Y. 1977. "Mixed Pricing in an Oligopoly." Journal of Economic Theory 14: 373-388.

Sorenson, A. T. 2000. "Equilibrium Price Dispersion in Retail Markets for Prescription Drugs." Journal of Political Economy 69: 213-255.

Stokey, N. 1981. "Intertemporal Price Discrimination." Quarterly Journal of Economics 93: 112-128.

United States Department of Agriculture. National Agricultural Statistics Service. Market News Service Washington, D.C. various issues.

United States Department of Labor. Bureau of Labor Statistics. Employment, Hours, and Earnings from the Current Employment Statistics Survey. Washington, D.C. various issues.

Van Praag, B. and B. Bode. 1992. "Retail Pricing and the Costs of Clearance Sales: The formation of a rule of thumb." European Economic Review 36: 945-962.

Varian, H. 1980. "A Model of Sales" American Economic Review 70: 651-659. 
Villas-Boas, J. M. 1995. "Models of Competitive Price Promotions: Some Empirical Evidence From the Coffee and Saltine Crackers Markets." Journal of Economics and Management Science 4: 85-107.

Walters, R. G. and S. B. McKenzie. 1988. "A Structural Equation Analysis of the Impact of Price Promotions on Store Performance.” Journal of Marketing Research 25: 51-63.

Warner, E. J. and R. B. Barsky. 1985. "The Timing and Magnitude of Retail Store Markdowns: Evidence from Weekends and Holidays." Quarterly Journal of Economics 110: 321-352.

Washington Growers Clearing House. Annual Report. 1998 and 1999. Yakima, WA. 